"I am afraid, Sir," said he, "that you have /and mercury." My examiner threw himself thought the study of pharmacy beneath your back in his chair with the air of one who notice, but I can tell you that you will find it says, "this fellow is incorrigible," but very useful to you, unless you purchase your made no remark, and, after a short pause, he drugs at this Hall." Yes, these were his turned to the other examiners, and asked if words, "unless you purchase your brugs they wished to put any questions to me. AT THIS Hall." He looked at me as if he They shook their heads in ominous silence. expected a reply, but I made none, and he continued his examination. Everything went on smoothly until we came to the practice of medicine, when he desired me to describe the symptoms of nephritis. I stated them. "The treatment?" "Bleeding, low diet, \&c., \&c., and mercury to the extent of a gentle ptyalism." He started with astonishment, whisked off his spectacles, and began rubbing the glasses very energetically with his red silk pocket handkerchief. "What, Sir, mercury? Ptyalism in nephritis? Consider, Sir, consider, that here -you-have-a-case-of-acute inflammation."

When my examination commenced, there were four examiners at the table at which I was seated, but as the inquiry proceeded, these left the spot, one by one, until I remained alone with my examiner. Now, liowever, seeing that there was something the matter, they hastened back, and resumed their seats. I thought that they would re. ject me if I persevered, so knowing what they wished me to say, and not being anxious for the crown of martyrdom, $I$ amended (?) my answer, and said, "Mucilaginous drinks, and oleaginous purgatives."--'To be sure, Sir'; why conld you not say that at first? you are getting careless, Sir."- "What are the syinptoms of peritonitis ?"-I gave them. "Well, Sir, and what is your treatment?"-i felt ashamed of having given way in the former instance, and determining not again to be so cowardly, I replied, "Copious, Iocal, and general bleeding, fomentations, low diet, \&cc., and mercury to ptyalism。" A general start was given all round the tahle. I added, "I have been tanght to give mercury in every severe case of inflammation.""Where, Sir?"- "At St. Thomas's Hospital."-Oh, by Doctor Elliotson?"-"Y Yes, and by Dr. Roots."-_ Does Dr. Roots give mercury in inflammatory diseases?"-." "Yes, he does."-After a short pause my examiner resumed. "What are the symptoms of rubeola?" I gave them. "And what is the treatment, Sir? I do not ask you what you have been taught in town, but give me the treatment you have seen pursued in the country."-"I scarcely remember," I said, "having seen any cases of measles in the country."-" Indeed! Well, what is the proper treatment of the disease?". I replied, "If the disease be slight, it requires no treatment, beyond a dose or two of purgative medicine, and low diet for a few days." "And what, if the case be severe?"- "If there be severe bronchitis, I should treat it lite any other case of bronchitis, by bleeding

The following converstion then took place:1st Examiner.- "Well, gentlemen, I do not know whether it is your opinion that we should recommend this gentleman for his diploma. I know that he should not treat M.." 2d Ex,_" Nor'me."

3d Ex.- "I did not hear the former part of his examination."

1st $E x$.- "Why, he acquitted himself prefty well in the former part; but, really, his practice of medicine is most

3d Ex.- " But you must recollect that he has been educated at a peculiar school."

1st Ex.- "Yes, certainly. Al, well, Sir, you may retire. We will consider of it."

In due time I was called up to receive my diploma from the chairman, who exhorted me not to consider my education as completed, but to continue my studies, "especially in-(the practice of medicine, thought I; but no, not a word of that)-especially in aratomy." Now, my examination in anatomy had certainly been most superficial, but I had not been wrong in a single answer in it.

The above facts do not require any comment from me. I enclose my name and address, and am ready to verify them per. sonally, I am, Sir, your most obedient servaut,

August 16th, 1837.

Sigma.

\section{MR. WINSLOW'S GUIDE TO THF COLLEGE.}

\section{To the Elitor of The La NCET.}

SIR:-As the review which appeared in No. 727 of The Lancet, of a little work of mine, is calculated to injure my professional reputation, I hope and trust, in justice to me, you will give an immediate insertion to the following remarks in reply:-

In order to insure the insertion of this let. ter, I shall confine myself to one or two observations, which may have the effect of rrmoving the impression which the review in question is calculated to produce on the minds of the reader's of your Journal.

Notice has been taken of several typographical errors, and these have been pointed ont as specimens of my anatomical igno. rance. I will admit that there are some typographical inaccuracies in the "Guide" which 1 corrected in the proof sheets; but which, through the gross carelessness of the $c^{\text {ompositor, were not attended to prior to the }}$ 
work finally going to press; but, surely, every medical work might be held up to ridicule, if the reviewer thought fit to hunt ont these typographical errors, and bring them forward as proofs of the ignorance of the writer.

Your reviewer never could have thought, that in speaking of the origin of a particular muscle, that the word "organs," for origin, was used by me intentionally. This is so evidently an error of the compositor that $I$ think, in common fairness to me, it ought to have escaped criticism.

As a specimen of a few " blunders," your reviewer gives the following as a quotation, which he says, "will satisfy the most lenient of critics." These words are not placed in inverted commas, but it is evident he intended his readers to suppose that it was an extract from my work :-

"The thorax and abdomen form one great cavity in the body." What I say is this :"Two great cavities in the body (meaning the skeleton), one anterior and inferior, comprising the thorax and abdomen; the other, posterior and inferior, formed by the union of the vertebral canal with the cranial cavity" (page 2 of the "Guide"). In page 99, of Di. Quain's " Elements of Anatomy," the same "blunder" is committed, if it is to be considered as one.

Again, I am made to say that "the gustatory nerve enters the angular foramen of the lower jaw." I say no such thing, and why should I be held up to censure, for words I never used? At page 19, to which you refer your readers, $I$ do not say what passes through the angular foramen!*

Agrain, in speaking of scirrhus of the testicle, the reviewer" makes me say that, "the tumour forms beneath the emulgent artery." The following are my words:- "the testicles are tuberculated on the surface; the spermatic cord is enlarged; the (it should have been a) tumour forms beneath the emulgent artery."

By referring to the latest edition of Sir Astley Cooper's Lectures on Surgery (page 382), which I believe were originally published in The Laxcet, your reader's will perceive that I use Sir A. Cooper's ou'n uords; conserquently, the blunder is his, and not mine.

Perhaps, in conclusion, you will allow me to say, that in the second edition of the "Guide" just published, all the errors which, through the unpardonable carelessness of the compositor, were allowed to remain uncorrected, are removed, and $I$ still Hatter myself that the work will be useful to students preparing for their examination. Trusting for the insertion of this letter to

"Mr. Winslow does not, " totidem verbis," say this, but the manner in which he describes the eustatory nerve, as being protected by the internal lateral ligament, justifies the statement which we made. that spirit of impartiality which ought to influence every public journalist, I remain, Sir, your obedient, humble servant,

Angust 13, 1837.

F, WINSLOW.

* The charges of misquotation contained in the foregoing letter are well replied to by the author himself in that document, but as Mr. Forbes Winslow affects to believe that we have done him injustice in the brief catalogue of blunders which we compiled from his "Guide," we shall take the trouble to make another series of extracts from that imbecile production. It contains abundant proofs, and to spare, that in bestowing ridicule on his pretensions to a knowledge of anatomy, we were not indebted, for the grounds of comment, simply to typographical crrors. Truly enough, we did laugh at some of these. Who could help it when, by a misprint of molar for malar, the jaw-teeth were taken from a man's mouth, and transferred to the neighbourhood of his eyes? But we also lost all patience at the number of errors of the press. A few might have been unavoidable in a great work; bul here was a "Pocket Guide," expressly professing to cram the student's head with shor't terms, and not ideus, - that circumstance in itself more especially demanding exactness of spelling, -every page of which contained an error, nay, hardly a term in the whole concern seemed to be free from incorrect orthography, or to be intelligibly expressed. These are not "faults of the compositor." That excuse cannot be pernitted. Mr. F. Winslow's "longings after immortality" must be very peculiar, when he can allow his production to be ornamented with printer's Latin. Its publication was certainly the author's own act,- - his own means of acquiring "respect for his professional reputation." But let us descend to minutix. Although the task will occupy considerable space, yel the occasional exposure of such impositions on the "pocket" of medical students, is worthy of the room, for the good effects produced will not be limited to the scribblings of a single author.

We accused Mr. F. Winslow of stating in a book which is intended for the use of students who are about to present themselves for examination at the Colleges of Surgeons, that the thorax and abdomen form one great cavity in the body. His words are,- 
"Two great cavities in the body-one, anterior and inferior, comprising the thorax and abdomen," \&c. Now, if it do not logically and necessarily follow from these words that the thorax and abdomen form one great cavity in the body, never more will we attempt to criticise. Mr. Winslow, in his letter, endeavours to father his blunder upon Dr. Quain. We have no time now to refer to Quain's "Anatomy," though if that learned author have really written body instead of skeleton we would advise Mr. Winslow to seek another authority for his chamber anatomy on all future occasions. But, in fact, Mr. Winslow might as well refer us to Dr. Quain for the very curious statement, that there are only two arteries in the human body. But, pray, from what system of anatomy did he obtain the following question and answer? (p. 39)-“ How many ventricles are there in the brain?Four ; two lateral, a middle, and an inferior one." Perhaps, however, this also is a misprint.

Having disposed of Mr. Winslow and $\mathrm{Dr}$. Quain, we turn to Mr. Winslow and Sir Astley Cooper, for the author of the "Guide" has a method which is peculiar to himself, of shifting his errors up on other people. Under the head scirrhus (in the "Guide") we find the following words:"This is a rare disease; it begins in the body of the testicle, with an extremely hard swelling; it feels like a marble body within the scrotum. The testicles are tuberculated on the surface; the spermatic chord is enlarged; the tumour forms beneath the emulgent artery." Now, to what can "the tumour" possibly refer in the above sen. tence, unless it be to the term scirrhus? and any student, on reading the passage, would inevitably conclude, that the emulgentartery was situated somewhere in the neighbourhood of the testicle. Yet the blundering author coolly assures us that if this be an error, Sir Astley Cooper is " particeps criminis ;" and, moreover, assures our readers that he has quoted Sir A. Cooper's own words. On referring to Sir A. Cooper's lectures on diseases of the testicle, published in THE LANCET, vol. iii., p. 32, we find the following sentence:- "After the spermatic chord has become enlarged, a hard tumour forms beneath the emulgent artery, which may be felt through the abdominal parietes." - Reader, have we misrepresented Mr. Forbes Winslow ? or has Mr. Forbes Winslow, after misquoting Sir A. Cooper, had the effiontery to charge the Hon. Baronet with the blunder of the ignorant Mr. Winslow?

So much for errors already exposed once, and now doubly exposed. Now for a few fresh examples. In reviewing his precious specimen of what compression can effect in literature, we stated that $\mathrm{Mr}$. Winslow was totally unfit to write either Latin or English; we did not furnish many proofs of this, conceiving a few examples to be sufticient, but we shall now reinforce them with some from the English side, lest Mr. Winslow make a second appeal upon that score. His Latin, being the fabrication of his printer, we will say no more thereon. The following are examples of choice English composition :-

"Muscles of the tongue. In the middle there is the genio hyo-glossus; more outward is the linguales; more outward still is the stylo-glossi; next to that the hyo-glossi ; next the palato-glossi." (P. 17.)

"In applying a ligature to an artery, the middle and internal coat is cut through." (P. 4 )

The author of the "Guide" is not even acquainted with some of the most familiar methods of expression in surgery. Thus he says "Dislocation of the os humeri, in the axilla, and dislocation of the femur in the foraman ovale."

To the instances cited in our last notice of Mr. Winslow's proficiency in anatomy, we add a few other's which the author of the "Guide" will find it rather difficult to fasten on "Quain's Anatomy."

At page 29 he enumerates the pectoralis major, and the pectoralis minor, amongst the musiles arising from the scapula. The scapula, he informs his readers, has two surfaces, one anterior, and one superior.

The cavities of the vestibule, cochlea, and semicircular canals, are said to be lined with the portio mollis of the 7 th pair. This must be a new discovery. We never before heard of nervous filaments being traceable throughout the semicircular canals.

In describing the ligaments of the hip. joint, Mr. Guide forgets the capsular liga. ment. He also omits to mention two of the ligaments attached to each rib.

In the surgical department the genius of Mr. Winslow shines yet more effulgently. While giving directions for tying the femoral artery, Mr. Winslow says, "In taking up the femoral artery, divide skin, superficial fascia, perhaps vena saphena major, superficial set of lymphatics, then the fascia lata femoris."

This is excellent. Perhaps vena saphena major ! And, mark, Mr. Winslow uses the imperative mood. What a smart off-hand surgeon he must be at an operation. Were he to describe the steps in lithotomy, he would, by analogy, speak thus :-_" In cutting down on the membranous portion, make oblique incision into integuments, three inches long; cut through superficial perineal fascia; divide transverse muscle, deep fascia, perhaps internal pudic artery, \&c."

We have already exemplified Mr. Winslow's peculiar ideas on the anatomy of the 
brain; some of his opinions on the diseases of that organ are not less heterodox. Thus, "It is necessary, in order to bring the brain back again to its natural state, in concussion, that inflammation should be established; but nature is not capable of keeping the inflammation within due bounds, and it goes on until it becomes a disease." Fortunately for those who are, from time to time, like our brethren in Ireland, liable to receive knock-down blows on the head, this theory is altogether erroneous. Loss of voluntary power, consciousness, and intelligence, after a violent blow on the head, must depend on a greater or less degree of concussion of the brain, unless extravasation be produced; and every practical man knows, that many persons recover from the effects of stunning injuries, without the slightest evidence of inflammation of the brain supervening.

But enough of this. The army of ignorant and illiterate pioneers for our medical youth, will probably lose a recruit in Mr. Forbes Winslow, who, most likely, will not again join their ranks until he has, at least, doffed his printer's Latin, added a fifth ventricle to his unfortunate brain, and assured himself, by private practice, that living arteries do not grape; and then he may take front rank in the troop.

\section{INQUEST ON THE BODY OF AN INFANT FOUND DEAD.}

\section{To the Editor of THE LANCET.}

SIR:-Although we are daily furnished with examples of the deplorable and inefficient methods of performing the coroner's duties at inquests, perhaps a more prominent example has not recently occurred than that which is furnished by the report of an inquast held in the Spitalfields' Workhouse.

The body, that of an infant, was found under extremely suspicious circumstances. Mr. Byles, the surgeon, stated that he found "several superficial wounds on the trunk and arms ; the lips and tongue much swollen and discoloured; and a mark round the neck as if it had been tightly confined; left scalp exceedingly tumefied and discoloured; left eye much blood-shot; left side of the face briised; and blood coming from the nostrils." Internally he found " the lungs fully expanded, and a portion, cut off, flucted in ucuter, being the usual test of previous respiration, and, consequently, of previous life. In the head, left parietal bone much more yielding, and, in the centre, it appeared bruised and crushed; a considerable coagulum beneath the dura mater, corresponding with the injury of the bone and the contused scalp; also a coagulum of blood at the base of the brain. The heart contained a moderate portion of coagulated blood. Stomach empty, and intestines contained that which showed that it had been suckled." Mr. Byles goes on to state,"I consider that the child had not only been born alive, but had lived many hours. From the appearance of the body at the time of examination, I consider that it had been dead, at least, forty-eight hours."

It appeared, furtber, from the evidence of the policeman, that the infant's clothes were saturated with blood.

Yet, Sir, upon this evidence, upon which every honest man, in his senses, would strongly suspect and infer the existence of foul play before death, the coroner charged the jury,--" That the infant might have died by a fall. With respect to the lungs floating in water being the test of an infant being born alive, that doctrine had been now exploded, for it had been subsequently ascertained that the lnngs of infants, who had been born dead, had floated in water." The coroner then read extracts out of a work on parturition, to prove that such might have been the case in the present instance; if so, the jury would find their verdict accordingly.

Now, in this charge, it is first declared that the child might have died by a fall. Here is not only an admission, but an ab. solute assumption, that the child was born alice, but died a violent death. To the question of accidental, or wilful, violence, the coroner never thinks it necessary to direct attention. After admitting the life and violent death of the child, he next tells the jury, that the hydrostatic test, or the floating of the lungs in water, has been exploded, as the lungs of children born dead had floated in water, and such might have been the case in the present instance.

Now, Sir, I beg to ask Mr. Coroner to explain how it could happen that the child, born alive, and dying by violence, (see the first part of his charge,) could be the identical child born dead according to the second; and to reconcile the fact of the lungs float ing in water with the verdict he would have forced upon the jury.

Let me next assure the coroner, that he is grossly mistaken in his facts. The hy: drostatic test is not exploded, but is relied upon. The lungs of a foetus born dead may float in water; but this arises from the buoyancy acquired by air generated during decomposition, or, as it is termed, putrefaction. Now, the lungs are the parts of the body which undergo putrefaction more slowly than any other parts, and, consequently, in the absence of anything like putrefaction externally, we may fairly presume that the buoyancy of the lungs did not arise from putrefaction. But allowing a question even here, surely the coroner should have sought to explain that this buoyancy was to be distinguished from that 